\title{
Charting a path along the continuum of PMTCT of HIV-1, to elimination, and finally to eradication
}

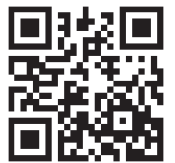

In this editorial we traverse the continuum of transmission of HIV-1 from mothers to children to highlight the biomedical history of this problem. Treatment has progressed from prevention with antiretrovirals (ARVs) through to a broader set of interventions, including various breastfeeding options and other health system improvements, that have increased the possibility of eliminating mother-to-child-transmission (MTCT) of HIV. At the far end of the continuum, the spectacular findings in the case of the Mississippi 'cured' baby indicate that eradication is possible.

HIV infections in children are overwhelmingly due to MTCT, ${ }^{[1]}$ intrauterine infections accounting for $10-25 \%$ of cases and intrapartum infections and those through breastfeeding for $35-40 \%$. High- and middle-income countries have had considerable success in preventing new HIV infections in children. All HIV-positive pregnant women in developed countries are treated with ARVs, so they have low viral loads (VLs) before and during delivery. In Europe and the USA, perinatal HIV-1 transmission occurs in only $1 \%$ of treated women with RNA virus loads $<1000$ copies $/ \mathrm{ml}$. With further suppression of viraemia, perinatal transmission may be eliminated. ${ }^{[2]}$ The World Health Organization (WHO) uses standardised transmission rates: $:^{[3]}$ the 2010 WHO-recommended regimens (options A or B) are estimated to be associated with a $2 \%$ probability of peripartum transmission and a $0.2 \%$ probability of transmission per month of breastfeeding. Peripartum and postnatal transmission probabilities were lowest for women who were taking antiretroviral therapy (ART) before the pregnancy, namely $0.5 \%$ peripartum and $0.16 \%$ per month of breastfeeding.

Intra-uterine and intrapartum transmissions account for the majority of transmissions in industrialised countries, whereas in developing countries breastfeeding (up to 24 months of age) can account for $30-40 \%$ of all MTCT. ${ }^{[1,4]}$ Interventions directed at all three routes of transmission have been very successful in industrialised countries, where transmission rates have fallen from $\sim 25 \%$ to $<2 \%$ and survival of infants has improved. ${ }^{[4]}$ In many middle-income countries transmission rates are now $\sim 2-3 \%$. In South Africa (SA), anecdotal data suggest that the transmission rate in the early 1990 s was $\sim 32 \%$. It was $2.5 \%$ in $2012 .{ }^{[5]}$

Summarising evidence for three levels of avoiding MTCT, we examine the experience of preventing MTCT globally, and suggest the probability of eliminating transmission, especially in South Africa (SA). Finally, we raise the question of eradicating new HIV infections in children altogether. Elimination and eradication are defined in Table 1.

\begin{tabular}{|c|c|}
\hline $\begin{array}{l}\text { Maternal disease } \\
\text { progression }\end{array}$ & $\begin{array}{l}\text { Death, WHO stage } 4 \text {, or } \mathrm{CD} 4^{+} \text {count } \\
<200 \text { cells } / \mu \mathrm{l}\end{array}$ \\
\hline Elimination & $\begin{array}{l}\text { Absence of clinical signs + undetectable viral } \\
\text { particles (in blood and other tissues), without } \\
\text { ARV use in a patient previously diagnosed } \\
\text { and treated for HIV; MTCT rate }<5 \%\end{array}$ \\
\hline Eradication & $\begin{array}{l}\text { Elimination }+ \text { absence of virus in previously } \\
\text { infected latent memory cells; MTCT rate }<2 \%\end{array}$ \\
\hline Amelioration & $\begin{array}{l}\text { Substantial improvement of clinical signs and } \\
\text { stable viral load in blood }\end{array}$ \\
\hline
\end{tabular}

We stress that much of the hard scientific data on prevention and elimination are already available; what is required are health service refinements. Eradication demands many more basic science experiments to confirm the results indicating 'cure' in the Mississippi baby, and to increase our understanding of the biology of latency and destruction of the replicative capacity of the virus. We need more information on the cellular and molecular environment of the $\mathrm{CD} 4^{+}$memory cells, and specific sites that harbour the virus. Among the prerequisites for eradication are public health studies to enable SA to scale up facilities and personnel for very early diagnosis and treatment.

\section{Prevention}

Numerous reviews of trials undertaken to prevent MTCT have demonstrated the efficacy of a number of interventions. In brief, these include ARVs, exclusive breastfeeding, and various health service measures such as "baby-friendly hospitals. ${ }^{[1,4,6,7]}$ The WHO has consolidated these data. ${ }^{[8,9]}$ In 2010 , deaths attributable to breastfeeding risk factors remained fairly high globally, suboptimal breastfeeding, for example, accounting for deaths of 293449 male and 251368 female infants. ${ }^{[1,11]}$ Figures for discontinued breastfeeding and non-exclusive breastfeeding are similar. ${ }^{[11]}$

A set of 'four prongs' as a framework to prevent MTCT of HIV-1 has been recommended by the WHO to tackle the problem comprehensively, and is critical in devising an effective and holistic approach to MTCT. ${ }^{[12]}$ Their implementation is key to both elimination of MTCT and eradication of HIV in children. The first prong aims at prevention of HIV in women, the second at prevention of unintended pregnancies in HIV-infected women, the third at prevention of transmission of the virus from mothers to their babies, and the fourth at care and support for HIV-infected women, their infants and their families. As part of the general progress in HIV health services in SA (see below), for example, the unmet need for family planning (i.e. the second prong) is $<5 \% .{ }^{[1,14]}$

SA has made considerable progress in confronting and driving back HIV-1 ${ }^{[5]}$ The government has launched an HIV counselling and testing campaign to reach 16 million people, rapidly expanded circumcision rollout, enhanced prevention of mother-to-child transmission (PMTCT) programmes, promoted integration of the treatment of HIV and tuberculosis, and drastically increased its budget to expand ART to 1.7 million people while simultaneously moving thousands of patients from PEPFAR-funded treatment programmes to government services. The impact of PMTCT programmes in SA is now evident at community level. Within 10 years of the start of the country's PMTCT programme, $95 \%$ of all health facilities were providing this service in 2010. SA is also one of four countries that have achieved over $80 \%$ coverage with ARV prophylaxis to prevent MTCT. More than $98 \%$ of women receive an HIV test during pregnancy, and $91.7 \%$ of HIV-positive mothers are receiving ART or prophylaxis. ${ }^{[14]}$ The national survey in $\mathrm{SA}^{[5]}$ showed that MTCT rates had fallen to $\sim 2.7 \%$ (95\% confidence interval $2.1-3.2 \%$ ) in 2011. This was confirmed by recently published global reports ${ }^{[13,14]}$ revealing that new HIV infections in SA children (aged 0 - 14 years) have continued to decline, with a fall of $63 \%$ (from 38000 to 14 000) between 2009 and 2012. Furthermore, $70 \%$ of eligible children are receiving ARVs. Transmission rates have fallen throughout the world, including SA, as coverage of MTCT services has increased to nearly $90 \%{ }^{\left[{ }^{[5]}\right.}$ 
SA's success in dealing with MTCT has been made possible by sound leadership, investments in infrastructure involving personnel, facilities and resources, and wider coverage of PMTCT programmes. In 2009 - 2013, 9 out of every $10 \mathrm{HIV-infected} \mathrm{pregnant} \mathrm{women}$ received ARVs for PMTCT and 9 out of every 10 infants received ARVs to prevent breastfeeding transmission. ${ }^{[14]}$ At the time of writing, there is universal access to ARVs, with $80 \%$ of eligible pregnant women receiving ART for their own health.

\section{Elimination}

We have recently drawn together health service changes that will be instrumental in eliminating MTCT. ${ }^{[15]}$ In essence, elimination requires escalation, intensification and improvement of the components of the WHO 'four prongs' approach described above. In particular, differential coverage of health services in developing countries has hindered progress, so PMTCT services ought to form part of universal coverage, and the gender-related interventions - primary prevention of HIV in women, family planning counselling, and voluntary and informed termination of unwanted pregnancies - should be integrated into comprehensive PMTCT programmes. Improved advocacy, information and guidance are required to increase public demand and use of these services. Within countries, implementation of recent WHO/UNAIDS ARV Guidelines ${ }^{[16]}$ promotion of breastfeeding and prevention of breastfeeding transmission, and continuing care of mothers and children are necessary.

\section{Eradication}

The news from a highly reputable group of researchers that a baby in Mississippi had been cured of HIV infection was greeted by widespread astonishment, clamorous voices of approval, unrestrained cries of delight and a storm of doubt. For more than 30 years the HIV epidemic has dominated our science and threatened our lives and health, the gloom brigade even questioning our survival. Cure seemed a distant yet ultimate goal - the 'holy grail' of modern scientific endeavour. And here was the first glimmer of a solution.

The mother presented in labour, so no ARVs were given before or during labour. The premature baby was HIV RNA- and DNApositive, but the VL was moderate when blood samples were tested at 30 and $31 \mathrm{~h}$. Samples from Mississippi were transported to a specialised laboratory, and in utero HIV infection was diagnosed. The virus isolated from the mother was replication competent and behaved like other wild-type or laboratory isolates, and neither mother nor baby had genetic markers typical of elite controllers. Mother and baby were started on ARVs $\sim 30 \mathrm{~h}$ before the diagnosis was known, with tests showing a decreasing VL over the baby's first month of life. Mother and baby were lost to follow-up (but the infant may have received 12 - 15 months of ART). The mother returned after 2 years, with her baby clinically well, not on ARVs, and seronegative. No HIV was identified by standard tests, but more sophisticated tests showed HIV DNA sequences of uncertain significance on occasional peripheral white blood cells.

The priority research questions were soon established by experts. For example, the currently available ARVs are not all suited for newborns, so an urgent priority is to work with pharmaceutical manufacturers to define the most useful formulations and to provide existing zidovudine/lamivudine dispersible tablets with score marks to allow them to be broken into quadrants of $15 / 7.5 \mathrm{mg}$. Some of us believed that the most suitable country to do the studies required to confirm and extend the findings was SA - and in fact the purpose of a recent symposium ${ }^{[17]}$ was to report on 'Scientific advances from the "Mississippi baby": Implications for public health programmes on MTCT of HIV. There are 12 recommendations, covering a broad range of fields ${ }^{[4,18]}$ Some of the public health proposals were to improve health services as laid out in recent WHO documents on elimination of MTCT, and more aggressive management of HIVexposed newborns. Challenges identified were diagnosis of HIV at birth, logistical constraints in testing HIV-exposed newborns, availability of the technology for diagnosis, encompassing better point-of-care tests, and appropriate ART for newborns.

A suggested package of interventions to 'eradicate' MTCT in South Africa includes optimising implementation of the evidencebased WHO 'four prongs' comprehensive strategy for PMTCT, improved health services, especially during the perinatal period, infancy and childhood, specifically addressing measures to reduce under-5 and maternal mortality, and improved diagnostic and therapeutic options.

\section{Additional evidence of 'cures'}

- The first and only reported case of a sterilising cure was Timothy Brown, the 'Berlin patient', who was HIV-infected and was given a bone marrow transplant for acute myeloid leukaemia. The donor was naturally resistant to HIV due to a mutation in the CCR5 gene, a critical protein required by HIV to enter and infect cells. Brown stopped ART very soon after transplantation and remains free of HIV after 6 years. ${ }^{[19]}$

- A French report (Visconti cohort) suggests that HIV has been eliminated in adults with chronic infection. This group of patients started treatment within 10 weeks of being infected and adhered to a course of ARV drugs for 3 years, on average, but then stopped. Some have remained under control for a decade..$^{[20]}$

- So-called 'elite controllers', who have undetectable VLs in the absence of ARVs, have been recognised for some time. ${ }^{[2]}$

\section{A Ramkissoon \\ H Coovadia}

Maternal, Adolescent and Child Health, Department of Obstetrics and Gynaecology, Faculty of Health Sciences, University of the Witwatersrand, Johannesburg, South Africa

\section{Corresponding author: H Coovadia (hcoovadia@match.org.za)}

\footnotetext{
1. Coovadia HM, Newell ML. Effective HIV prevention and treatment for pregnant mothers. Meeting health care needs. In: Heyman J, Sherr L, Kidman R, eds. Protecting Childhood in the AIDS Pandemic: Finding Solutions that Work. New York: Oxford University Press, 2012:169-194.

2. Ioannidis JP, Abrams EJ, Ammann A, et al. Perinatal transmission of human immunodeficiency virus 2. Ioannidis JP, Abrams EJ, Ammann A, et al. Perinatal transmission of human immunodeficiency virus
type 1 by pregnant women with RNA virus loads $<1000 \mathrm{copies} / \mathrm{ml}$. J Infect Dis 2001;183(4):539-545. type 1 by pregnant women with RNA
[http://dx.doi.org/10.1086/318530]

3. Rollins N, Mahy M, Becquet R, Kuhn L, Creek T, Mofenson L. Estimates of peripartum and 3. Rollins N, Mahy M, Becquet R, Kuhn L, Creek T, Mofenson L. Estimates of peripartum and
postnatal mother-to-child transmission probabilities of HIV for use in Spectrum and other population-based models. Sex Transm Infect 2012;88(suppl 2):i44-i51. [http://dx.doi.org/10.1136/ sextrans-2012-050709]

4. Rollins N, Coovadia HM. Breastfeeding and HIV transmission in the developing world: Past, present, future. Curr Opin HIV AIDS 2013;8(5):467-473. [http://dx.doi.org/10.1097/ COH.0b013e3283632ba2]

5. Goga AE, Dinh TH, Jackson DJ; for the SAPMTCTE study group. Evaluation of the Effectiveness of the National Prevention of Mother-to-Child Transmission (PMTCT) Programme Measured at Six Weeks Postpartum in South Africa, 2010. South African Medical Research Council, National Department of Health of South Africa and PEPFAR/US Centers for Disease Control and Prevention, 2012. http://repository.uwc.ac.za/xmlui/bitstream/handle/10566/462/GogaPMTCT2012.pdf?sequence=3 (accessed 5 November 2013).

6. Townsend CL, Cortina-Boria M, Peckham CS, et al. Low rates of mother to child transmission of HIV following effective pregnancy interventions in the United Kingdom and Ireland, 2000-2006. AIDS 2008;22(8):973-981. [http://dx.doi.org/10.1097/QAD.0b013e3282f9b67a]

7. Pérez-Escamilla R. Evidence based breast-feeding promotion: The Baby-Friendly Hospital Initiative. J Nutr 2007;137(2):484-487

8. World Health Organization. Rapid Advice: Use of antiretroviral drugs for treating pregnant women and preventing HIV infection in infants. November 2009. http://www.who.int/hiv/topics/mtct/ (accessed 15 June 2010).

9. World Health Organization. Antiretroviral Drugs for Treating Pregnant Women and Preventing HIV Infection in Infants: Towards Universal Access. Recommendations for a Public Health Approach (2010 version). 2010. http://www.who.int/hiv/pub/mtct/antiretroviral2010/en/index. html (accessed 15 November 2010).

10. Lozano R, Naghavi M, Foreman K, et al. Global and regional mortality from 235 causes of death for 20 age groups in 1990 and 2010: A systematic analysis for the Global Burden of Disease Study. Lancet 2013;380(9859):2095-2128. [http://dx.doi.org/10.1016/S0140-6736(12)61728-0]
} 
11. Lim SS, Vos TP, Flaxman AD, et al. A comparative risk assessment of burden of disease and injury attributable to 67 risk factors and risk factor clusters in 21 regions, 1990 - 2010: A systematic analysis for the Global Burden of Disease Study 2010. Lancet 2013;380(9859):2224-2260. [http://dx.doi. org/10.1016/S0140-6736(12)61766-8]

12. Sweat MD, Reilly KR, Schmidt GP, et al. Cost-effectiveness of nevirapine to prevent mother to child HIV transmission in eight African countries. AIDS 2004;18(12):1661-1671. [http://dx.doi. org/10.1097/01.aids.0000131353.06784.8f

13. World Health Organization. Programmatic Update. Use of Antiretroviral Drugs for Treating Pregnant Women and Preventing HIV Infection in Infants. Executive Summary April 2012. Geneva: WHO, 2012. http://whqlibdoc.who.int/hq/2012/WHO_HIV_2012.6_eng.pdf (accessed 21 September 2013).

14. World Health Organization. 2013 Progress Report on the Global Plan Towards the Elimination of New HIV Infections among Children by 2015 and Keeping Their Mothers Alive. Geneva: WHO/ UNAIDS, 2013. http://www unaids.org/en/../2013/20130625 progress_global_plan_en pdf (accessed 1 September 2013).

15. Coovadia HM, Govender T. Eliminating mother to child transmission of HIV-1 and keeping mothers alive: Recent progress. J Infect 2013 (in press). [http://dx.doi.org/10.1016/j.jinf.2013.09.015]

16. World Health Organization. HIV/AIDS Programme. Consolidated Guidelines on the Use of Antiretroviral Drugs for Treating and Preventing HIV Infection. Recommendations for a Public
(n) Antiretroviral Drugs for Treating and
Health Approach. Geneva: WHO, 2013 .
17. UNAIDS/CAPRISA. Report on the UNAIDS Symposium on the scientific advances from the 'Mississippi baby' and the implications for public health programmes to eliminate mother-to-child'Mississippi baby' and the implications for public health programmes to eliminate mother-to-child-
transmission of HIV, 3 - 4 June 2013, Durban, South Africa. https://www.facebook.com/permalink php?id=327735533989998 (accessed 22 September 2013).

php?id=327735533989998 (accessed 22 September 2013).
18. UNAIDS. 12 recommendations following a discussion about the 'Mississippi baby'. http://www. UNAIDS. 12 recommendations following a discussion about the 'Miss
unaids.org/en/resources/documents/2013 (accessed 12 September 2013).

19. Yukl SA, Boritz E, Busch M, et al. Challenges in detecting HIV persistence during potentially Yukl SA, Boritz E, Busch M, et al. Challenges in detecting HIV persistence during potentially
curative interventions: A study of the Berlin patient. PLoS Pathog 2013;9(5):e1003347. [http:// curative interventions: A study of the Berfing
dx.doi.org/10.1371/journal.ppat.1003347]

20. Sáez-Cirión A, Bacchus C, Hocqueloux L, et al. Post-treatment HIV-1 controllers with a long-term virological remission after the interruption of early initiated antiretroviral therapy. ANRS VISCONT Study. PLoS Pathog 2013;9(3):e1003211. [http://dx.doi.org/10.1371/journal.ppat.1003211]

21. Deeks SG, Walker BD. Human immunodeficiency virus controllers: Mechanisms of durable virus control in the absence of antiretroviral therapy. Immunity 2007;27(3):406-416. [http://dx.doi. org/10.1016/j.immuni.2007.08.010]

S Afr Med J 2014;104(1):18-20. DOI:10.7196/SAMJ.7603 